\title{
Comparison of Induction Motor Field Efficiency Evaluation Methods
}

\author{
Prepared by the \\ Oak Ridge National Laboratory \\ Mail Stop 8058, P. O. Box 2009 \\ Oak Ridge, Tennessee 37831-8058 \\ Managed by \\ Lockheed Martin Energy Research Corp. \\ for the \\ U.S. Department of Energy \\ under contract DE-AC05-96OR22464
}

CONF- $961096--3$

J. S. Hsu, J. D. Kueck, M. Olszewski, D. A. Casada, P. J. Otaduy, L. M. Tolbert

\begin{abstract}
Unlike testing motor efficiency in a laboratory, certain methods given in the IEEE-Std 112 cannot be used for motor efficiency evaluations in the field. For example, it is difficult to load a motor in the field with a dynamometer when the motor is already coupled to driven equipment. The motor efficiency field evaluation faces a different environment from that for which the IEEE-Std 112 is chiefly written. A field evaluation method consists of one or several basic methods. This paper separates and compares the basic methods according to their physical natures. Their intrusivenesses and accuracies are also discussed. This study is useful for field engineers to select or to establish a proper efficiency evaluation method by understanding the theories and error sources of the methods.
\end{abstract}

\section{INTRODUCTION}

Motor-driven systems use two thirds of the total electricity consumed by industry. Historically, energy efficiency improvements in these systems have been important for economic reasons only. However, these improvements have now assumed an environmental role in meeting the U.S. commitment to reduce greenhouse emissions.

There have been many articles concerning energy efficiency of induction motors [1-19]. In general, an energy efficiency improvement program includes development of a motor management plan that focuses on development of a plant motor inventory and an evaluation of motor performance for large or critical motors. The evaluation of motors focuses on the operating efficiency and motor load to identify energy efficiency gains and possible reliability improvements. This requires a reliable method for assessing motor performance in the field.

The majority of motors in the field are induction motors for which IEEE-Std 112 Test Procedure for Polyphase Induction Motors and Generators [10] would be applicable. However, field evaluation of operating efficiency introduces an environment for which IEEE-Std 112 is not applicable.
For example, IEEE-Std 112 requires that induction motor tests be performed with a voltage unbalance not exceeding $0.5 \%$ (note that this is significantly smaller than the NEMA MG-1 permissible limit of $1 \%$ [14] for successful operation of motors). However, field conditions may exceed this limit by a significant measure. Thus when evaluating motor performance in the field it is important to use a technique that can accommodate field conditions and yield results of sufficient accuracy for the evaluation needs.

There are many methods pertinent to field efficiency evaluation in the literature and new methods are appearing every year. The reader is encouraged to refer to a survey, "Assessment of Available Methods for Evaluating InService Motor Efficiency" by Kueck et al [1] for a rather complete list of references of efficiency estimation available either commercially or in the literature. This survey was prepared for the U.S. Department of Energy, Bonneville Power Administration and the Pacific Gas and Electric Company, and is available from the Bonneville Power Administration printing office.

A field evaluation method can consist of a single basic method or can be built using a combination of different basic methods. This paper separates and compares the basic methods according to their theoretical basis and error sources. This may help field engineers select or establish an efficiency evaluation method suited to their need.

The basic methods are:

nameplate method,

slip method,

current method, statistical method, equivalent circuit method, segregated loss method, air gap torque method, and shaft torque method.

An example illustrating a combination of different basic

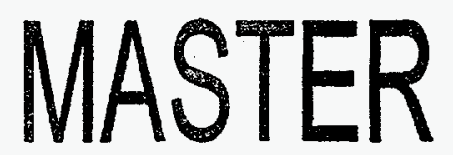

U.S. Government work not protected by U.S. copyright 


\section{DISCLAIMER}

Portions of this document may be illegible in electronic image products. Images are produced from the best available original document. 
methods is a modified version of the slip method established in conjunction with nameplate information and built-in statistical data. If applied properly, this combined effort normally improves the accuracy of the efficiency evaluation for a targeted group of motors. Regardless of how complex the combination is, the nature of each basic method affects overall accuracy of the combination.

All methods calculate efficiency according to the definition of

$$
\text { Efficiency }=\frac{(\text { Shaft output power })}{(\text { Electrical input power to drive system })}
$$

The shaft output power is the input power minus the losses. How to assess losses and evaluate output power gives rise to fundamental differences among the various methods. Consequently, the accuracies of methods are different.

The degree of intrusiveness of a field evaluation method is determined by what data are required to be measured in the field and how difficult to perform the measurements are. One or more of the following measurements may be involved:

nameplate reading,

speed measured by optotachometer,

currents measured by clamp-on transducer,

voltages measurement,

input power measurement,

stator winding resistance reading,

winding temperature data,

no load data measured with un-coupled shaft, and

shaft torque measurement.

The data may be acquired in the format of rms meter readings or digitally sampled waveforms.

The cost associated with the labor, material, and downtime for implementing safety requirements for data collections can be used as a gauge to weigh intrusiveness. For example, using an optical tachometer for rotating speed measurement normally has a lower intrusion level than a voltage measurement since it requires making connections in a terminal box. Intrusiveness can vary from plant to plant. For the same example, if the voltage transducer is permanently installed and wired to proper connectors, the intrusiveness is significantly lower.

Planning may also affect intrusiveness. If a decoupled, no-load test is required and the motor power supply is available during scheduled downtime, it may be possible to conduct this kind of test without affecting production. If, however, the data are to be taken during production time, the cost and intrusion level would be very high.

\section{Physical Natures of Basic Methods}

In this section the physical basis of each basic method is described in terms of how the efficiency is obtained and of the potential errors associated with it.

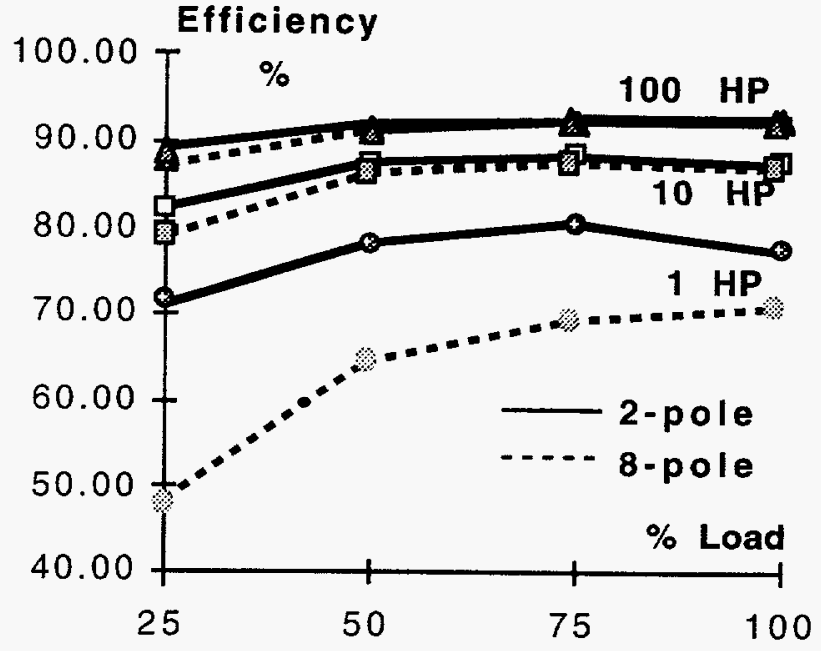

Fig. 1 Typical efficiency versus load curves

\section{A. Nameplate Method:}

The least intrusive field evaluation method is to obtain motor information from the nameplate. In this method it is assumed that the efficiency of the motor is constant and equal to the nameplate value. This works best when the efficiency-load curve is fairly flat so that the full load efficiency is applicable for most load conditions.

The typical load factor of industrial motors is around $75 \%$ [19]. Using typical efficiency versus load curves for motors having various poles and horsepower ratings we can evaluate the potential accuracy of the nameplate method. As indicated in Fig. 1, the efficiency is not a strong function of load for a 2-pole motor between $50 \%$ and $100 \%$ of load. However, the efficiency of an 8-pole, 1-hp motor shows a marked decline over that load range. Hence, the nameplate method may be applicable for some motors but could result in substantial inaccuracies for other motor types.

For this nameplate method, three additional problems may occur. First, the nameplate data may be given according to a method other than the IEEE-Std 112 Method B. Second, the motor may have been rewound. Third, the field environment pertinent to the voltage unbalance and harmonics content may be different from that for which the nameplate data is derived.

Nameplate efficiencies of a given motor can be evaluated according to different standards. The three most frequently used standards are the National Electrical Manufacturers Association (NEMA) that uses IEEE standard 112, the Japanese Electrotechnical Committee (JEC), and the International Electrotechnical Commission (IEC). These three standards are not in agreement $[12,13]$ and may result in a given motor stamped with rather different efficiencies. A typical example given in [11] shows the confusing international nameplate data situation:

\begin{tabular}{|l|l|l|}
\hline $\begin{array}{l}\text { IEEE 112 } \\
\text { Method B }\end{array}$ & JEC37 & IEC34-2 \\
\hline $90.0 \%$ & $93.1 \%$ & $92.7 \%$ \\
\hline \multicolumn{2}{|c|}{ Per H. Jordan and A. Gattozzi, 1979 [11] } \\
\hline
\end{tabular}


Rewound motors introduce additional uncertainty since the nameplate data may no longer be valid. Core loss of a rewound motor may or may not be increased depending upon the lamination insulation and the cleaning process of the stator. The copper loss depends on the new coil extension and wire gauges. Certain engineers suggest that after each rewinding to the same horsepower and same number of poles a two percentage points reduction of efficiency should be considered. However, a different opinion indicates that the efficiency should not be reduced if the rewinding follows EASA (Electrical Apparatus Service Association) standards.

The field environment pertinent to the voltage unbalance and harmonics content is commonly worse than that from which the nameplate data are derived

The worst situation for a field efficiency evaluation using the nameplate method is having a less than $10 \mathrm{hp}$, low speed, rewound motor that was not repaired according to EASA Standards. The motor has non IEEE-112 Method B data stamped on the nameplate and is operated under a polluted supply (voltage unbalance or harmonic distortion). The efficiency can easily be off ten percentage points from the nameplate efficiency. However, the bottom line is that a nameplate method is better than no field evaluation at all.

\section{B. Slip Method:}

This method presumes that the percentage of load is closely proportional to the percentage of the ratio of measured slip to full-load slip. The shaft output power is thus approximated using the following relationship:

$$
\begin{aligned}
& \text { (Shaft Output Power }) \\
& \qquad=\frac{(\text { Measured Slip) }}{(\text { Rated Slip })} \cdot(\text { Rated Output Power })
\end{aligned}
$$

where slip is a function of motor speed given by the ratio of the difference of synchronous speed and motor speed to the synchronous speed. Motor speed can be measured by an optical tachometer which has a low intrusion level. Input power must also be measured, which has a higher degree of intrusion.

The slip method can be an improvement over a pure nameplate method. Specially when the motor efficiency versus load curve is not flat. Any method that uses slip to estimate percentage of load is related to the slip method.

Once the shaft output power is known, one may use a typical efficiency versus load curve specifically for either standard, high, or in between efficiency motors similar to the one shown in Fig. 1 to assess efficiency. Alternatively, one may combine the basic slip method with other additional measurements, such as the input power which has a higher degree of intrusion, to obtain efficiency through eqn. (1).

NEMA MG-1 Section 12.46 [14] states that variation from the nameplate speed of ac integral horsepower induction motors shall not exceed $20 \%$ of the difference between synchronous speed and rated speed when measured at rated voltage, frequency, and load and with an ambient temperature of 25 degrees $C$. This means that the nameplate slip can be $20 \%$ inaccurate when the motor is operating in the field thus introducing significant inaccuracies in eqn. (2).

The no load speed of induction motors is always close to the synchronous speed. Subsequently, the projection of a light load through the basic slip method is relatively more accurate than the projection of a heavy load.

\section{Current Method:}

This method presumes that the percentage of load is closely proportional to the percentage of the ratio of measured current to full-load current. The shaft output power is thus approximated using the following relationship:

$$
\text { (Shaft Output Power })=\frac{I}{I_{f l}} \cdot(\text { Rated Output Power })
$$

where $I f l$ is the nameplate full load current and $I$ is the measured current.

Fig. 2a shows a circle diagram of an induction motor. For small integral horsepower motors the no load current may not be greatly reduced from the full load current. Fig. $2 b$ shows a source of error when eqn. (3) is used to assess the shaft output power; the assumed load versus current curve used by eqn. (3) is further apart from the actual curve at light loads. This is just opposite to what the basic slip method is relatively good for. The load is normally overestimated.

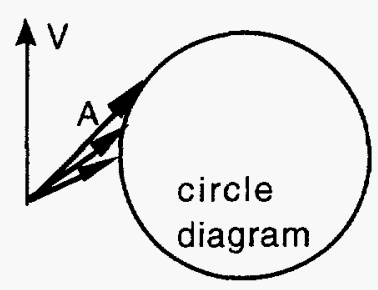

(a)

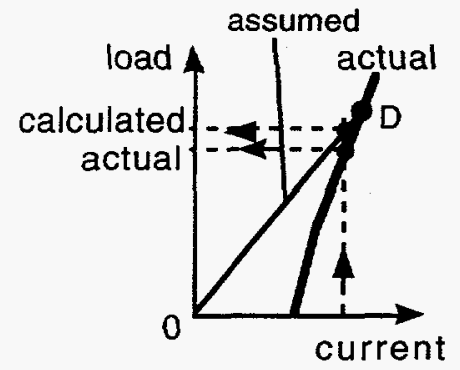

(b)
Fig.2 (a) Circle diagram showing current locus of induction motor. (b) Assumed and actual load versus current curves with full load current data point, D.

The expression of shaft output power defined by eqn. (4) requires that the no load current, Inl, be known. This may increase the intrusiveness substantially when a no load test is required.

$$
\begin{aligned}
& \text { (Shaft Output Power) } \\
& \qquad=\frac{\left(I-I_{n l}\right)}{\left(I_{f l}-I_{n l}\right)} \cdot(\text { Rated Output Power })
\end{aligned}
$$

Fig. 3 shows that the load evaluation is normally underestimated when eqn. (4) is used. The average of the two approaches of eqns (3) and (4) may give a more 
accurate shaft output power.
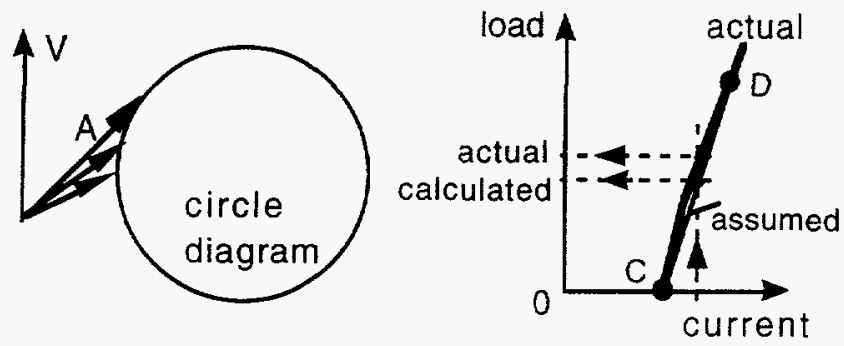

Fig.3 (a) Circle diagram of induction motor. (b) Assumed and actual load versus current curves with full load and no load current data points, $\mathrm{D}$ and $\mathrm{C}$.

NEMA MG-1 Section 12.47 states that when operated at rated voltage, rated frequency, and rated horsepower output, the input in amperes shall not vary from the nameplate value by more than 10 percent. This is another source of errors for the current methods.

Motor current measured by a clamp-on probe corresponds to a relatively low level of intrusiveness. The insulation of motor leads and terminals is not disturbed. The measured current is used to estimate the load of a motor. The simple current method does not require a no load current value.

Just as with the slip method, to obtain efficiency one will have to either use typical efficiency versus load curves or measure input power.

\section{Statistical Method:}

Empirical equations are set up to use minimal numbers of measured data for input power and efficiency estimations. Usually application of this method is restricted to the group of motors for which empirical equations were derived.

If the statistical results are not used for the group of motors that the empirical equations are based on, significant errors in the efficiency estimation are likely.

The statistical results can be quite different for the same variable. A good example is the stray load loss estimation. NEMA MG1 [14] paragraph 20.52 states that if stray load loss is not measured, the value of stray load loss at rated load shall be assumed to be $1.2 \%$ of the rated output for motors rated less than $2500 \mathrm{hp}$ and $0.9 \%$ for motors rated $2500 \mathrm{hp}$ and greater. IEEE Std 112 [10] Section 5.4.4 gives different assumed stray load loss values for motors rated less than $2500 \mathrm{hp}$. They are:

$$
\begin{array}{ll}
1-125 \mathrm{hp} & 1.8 \%, \\
126-500 \mathrm{hp} & 1.5 \%, \text { and } \\
501-2499 \mathrm{hp} & 1.2 \% .
\end{array}
$$

Additionally, certain non U.S. standards use $0.5 \%$ of rated output as the stray load loss at rated load.

The statistical approach is commonly used with other basic methods. For instance, Ontario Hydro 1 has published a segregated loss method that simplifies IEEE Std 112
Method E1 much further. As pointed out in this study, it is not always possible to interrupt a process long enough to decouple a motor from its load and conduct a no load test. The study suggests that one way around this obstacle is to assume a value for the combined windage, friction and core losses. This method suggests that these combined losses be set to 3.5 percent of input rated power. The stray load losses are estimated based on the IEEE 112 standard assumed values.

This method can be simplified even further by using assumed values for rated power factor. Approximations can also be made for the temperature rise of the winding, and even the winding resistance can be estimated by measuring the line-to-line resistance taken from the circuit breaker and subtracting the estimated cable resistance. The only other measurements required are power into the motor and motor speed.

\section{E. Equivalent Circuit Method:}

Efficiency assessed through an equivalent circuit method is based on the impedance values of an equivalent circuit shown in Fig. 4. The circuit represents the fundamental portion of a complex equivalent circuit shown by Alger in Fig. 9.6 of reference [5]. The six impedances are: stator resistance $r_{l}$, stator leakage reactance $x_{l}$, magnetizing reactance $x_{m}$, core-loss resistance $r_{o}$, rotor leakage reactance $x 2$, and rotor resistance $r$. The slip $s$ affects the load of the equivalent circuit.

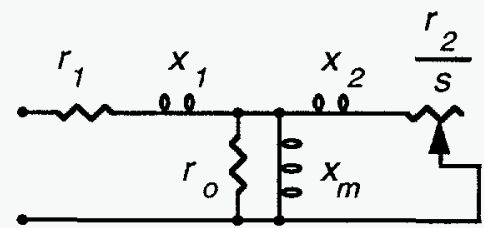

Fig. 4 A six-impedance equivalent circuit

The advantage of equivalent circuit method is that the performance of a motor can be predicted at any load when the impedance values are known. On the other hand, the impedance values can change a great deal when the motor speed varies between standstill and no load due to deep bar effects and magnetic saturation. There are different approaches for obtaining the impedance values.

When the six-impedance equivalent circuit is used, all the losses other than the friction and windage loss that are not represented by the stator copper, rotor copper, and noload core-loss resistances, are lumped to a collective loss named stray-load loss.

The IEEE Standard 112 Method F is an example of an equivalent circuit method. It is not a useful field test for efficiency. As is true for Method $\mathbf{E}$, its additional removedrotor and reverse-rotation tests to directly measure the fundamental frequency and high frequency stray load losses are too invasive and user unfriendly. Therefore, we will restrict our attention to Method F1.

The basic Method F1 requires an impedance test and the complete no load, variable voltage test. The version of 
Method F1 believed more suited to field use requires volts, watts, amperes, slip, stator winding temperature, or stator winding resistance to be measured at two values of voltage while operating at no load. In one case, measurements are made at rated voltage while operating at no load. In the other case, measurements are made while operating at no load with voltage reduced until slip is equal to that obtained at the normal operating load. Once these measurements are made, an iterative procedure is used to determine the parameters of the equivalent circuit. The iterative procedure requires one to either know the design value of the ratio $\mathrm{X} 1 / \mathrm{X} 2$ or to use the standard NEMA design value. Although this method is expected to be quite accurate, it is still considered to be too intrusive for routine field use.

A no-load test provides data for determination of magnetizing reactance and core, friction and windage loss resistance. A low-frequency locked-rotor test gives values for stator and rotor reactances and resistances. Simplified methods without conducting locked-rotor and no-load tests are possible.

Slip is an important parameter for the load calculation. The performance of an electric motor, at least with regard to efficiency, can be calculated from its equivalent electric circuit. Equivalent circuit methods permit one to compute estimates of the efficiency of the motor when it is operating at loads other than those at which measurements were made.

The basic methods of statistical and nameplate methods can simplify the determination of impedance values. A typical example is the Oak Ridge National Laboratory's (ORNL) Nameplate Equivalent Circuit Method described in Ref [1]. It is a modified version of IEEE Std 112 method-F, in which an extra resistance has been added to the rotor circuit to account for stray losses since they are mostly dependent on rotor current. Once the values of each of the equivalent circuit components are known accurately, as shown below, efficiency may be obtained from the measurement of the motor's speed.

Two low-intrusion approaches can be followed to determine the values of the augmented seven components in the equivalent circuit. Both rely on the motor's nameplate data and NEMA standards. The first approach requires the measurement of stator resistance $(r l)$ at rated load temperature. The second approach estimates $r I$ using generic relationships based on the number of poles $(N p)$, horsepower rating $(H P r)$, and rated line voltage $(V r)$ of the motor. The second approach does not require any measurements specific to the motor of interest: all motors with the same nameplate data will be found to have the same equivalent circuit. Consequently, their efficiency in the field will be estimated differently only if their speed is different.

Once $r_{l}$ is known, the rest of the parameters are found as follows:

The nameplate's rated horsepower, voltage, current and either power factor or efficiency allow the computation of the rated power input and overall motor impedance $Z T$ and efficiency or power factor respectively.
From the rated power input and IEEE 112, the loaddependent stray losses can estimated as a percentage ( $S L \%$ ) of the rated power output at rated load weighted by the ratio of rotor-current-to-rated-rotor-current squared. From this the value of the stray load resistance $r s L$ is determined.

The friction and windage losses are taken as a constant percentage $(F W \%)$ of the rated power input where $F W \%=$ $1.2 \%$ for 4 pole motors below $200 \mathrm{hp}$. This loss allows us to determine the appropriate raw-efficiency for the equivalent circuit of the motor at rated conditions.

The nameplate speed and number of poles yields the rated slip $(s r)$ which links the power output to the rotor's ohmic loss.

The nameplate NEMA Class - A, B, C, or wound rotor provides a value for the ratio between the stator and rotor leakage inductances ( $x_{1}$-to- $x_{2}$-ratio) $-1.0,0.67,0.43,1.0$ respectively.

The nameplate NEMA Code letter - D, E, ... L - brackets the value of the locked rotor current - from 5 to 12.5 times horsepower rating. One can chose to pick the midpoint of the range corresponding to the motor's Code letter. This, together with the rated Voltage, allows the computation of the magnitude of the motor's impedance under locked rotor conditions.

The rated slip, overall resistance and inductance, $x_{I}$-to$x 2$-ratio and magnitude of the locked rotor impedance can then be used to iteratively find the values of $x_{1}, x_{2}, r_{2}$ and $\mathrm{Zm}$ that yield the raw efficiency for rated conditions and also satisfy the locked rotor current condition.

Finally the magnetizing impedance $Z m$ yields readily the values of its constituents: the core resistance $(r o)$ and the magnetizing inductance $\left(x_{m}\right)$.

The values of the equivalent circuit components found above : $r 1, x_{l}, r 0, x_{m}, r 2, x_{2}$, and $r_{2 s L}$ - can then be used to compute the motor's raw efficiency at any load and voltage from the measurement of motor speed. The net efficiency is found by subtracting the friction and windage losses from the motor's raw power output.

Another example of equivalent circuit method for field efficiency evaluations is the "Ontario Hydro's Simplified Method F1". It is described in Ref. [1].

\section{F Segregated Loss Method:}

The segregated loss method estimates the magnitudes of the five losses, namely: stator copper loss, rotor copper loss, core loss, stray load loss, and friction and windage loss. The shaft output power is the input power minus the losses. Some of the methods in this category are quite complicated and intrusive, while others rely on empirical factors to estimate the losses.

There are quite a number of available methods that are based on the evaluations of the five losses. One good example is the IEEE Std 112 Method E. A literal interpretation of method $E$ is not a useful field test for efficiency. Its additional removed-rotor and reverserotation tests used to directly measure the fundamental 
frequency and high frequency stray load losses are not practical for field efficiency evaluation. Therefore, attention will be restricted to method E1. Even a literal interpretation of Method E1 would be impractical for field use, because it requires a variable load and a variable voltage power supply. Method El specifies an assumed value for stray load losses at rated load. The repeatability of Method El is improved by requiring the adjustment of all resistance and slip measurements to a specified temperature.

However, in many available methods, the principle of segregating motor losses into five losses remains the same as that used in Method E1. Statistical methods are always in conjunction with the segregated loss method to simplify the procedures required by Method E1. Once the voltage, current, power and speed data has been collected, the algorithms provided in IEEE 112 are used to calculate the individual component losses.

Commercial devices are available for measuring the efficiency of installed motors based on a modified version of the IEEE Standard 112, Method E1. These also require a measurement of power in, winding resistance, and speed. There are also various empirical methods that use approximations of the various losses to develop an overall loss estimate.

\section{G. Air Gap Torque Method:}

The air-gap torque method uses the product of air-gap torque and rotor speed as the air gap mechanical power for efficiency evaluation. The more sophisticated air-gap torque method developed at ORNL uses current and voltage waveforms as input data. The waveform data acquired can also be used for defect detections [7] on cracked rotor bars, stator turn-to-turn shorts, and for evaluation of harmonic contents of voltage and current. The efficiency is calculated as below:

The input power of a three-phase induction motor is the average summation of products of the instantaneous phase voltages, $v_{a}, v_{b}, v_{c}$, and phase currents, $i_{a}, i_{b}$, and $i_{c}$.

$$
\text { Power }=\frac{\int_{0}^{\text {period }}\left(v_{a} i_{a}+v_{b} i_{b}+v_{c} i_{c}\right) d t}{(\text { period })}
$$

The air-gap torque equation is

$$
\text { Torque }[N m]=\frac{P}{2 \cdot \sqrt{3}}\left\{\begin{array}{c}
\left(i_{A}-i_{B}\right) \cdot \int\left[v C A-R\left(i C-i_{A}\right)\right] d t \\
-\left(i_{C}-i_{A}\right) \cdot \int\left[v_{A B}-R\left(i_{A}-i_{B}\right)\right] d t
\end{array}\right\}
$$

where

$$
\begin{aligned}
P & =\text { number of poles } \\
i_{A}, i_{B}, \text { and } i_{C}= & \text { line currents } \\
R= & \text { half of the line-to-line resistance } \\
& \text { value. }
\end{aligned}
$$

$$
\eta=\frac{\left[\begin{array}{l}
(\text { Air gap torque }) \cdot 2 \pi \cdot \frac{(\mathrm{rpm})}{60} \\
-(\text { Friction windage loss })-(\text { stray loss })
\end{array}\right]}{\text { (Input power })}
$$

When the balanced power supply contains negligible harmonics, various modified versions based on Method E1 of the IEEE 112 standard [10] can be quite accurate for conventional induction motor field efficiency evaluations. The waveforms acquired by the air-gap torque method may be used to calculate the power and harmonic content in detail. However, this is not the most important difference between the air-gap torque method and Method E. The fundamental difference between these two methods is as follows.

Some engineers may have an unrealistic expectation on Method E, and suggest that under any load situation of a motor, the losses produced by the negative fields associated with unbalanced supply voltages and harmonics are included in the no-load loss. These negative sequence fields are not changed at either full load or no load, because the speed difference between full load and no load is small. Consequently, the slip is practically not changed, and the negative sequence impedance as well as the negative sequence currents remain the same. Under any load the loss associated with the negative sequence fields is the same as this loss at no load.

This expectation is not correct for motors operating in the field. In the real world, the supply has an impedance. The motor terminal voltages do change some as the load varies. Table 1 shows the tested fundamental frequency voltages and currents of the positive and negative sequence components under an unbalanced supply. When the load goes up and further upsets the voltage balance, the negative sequence voltage increases. The varied ratios of negative sequence voltages to currents indicate that the negative sequence impedance is not a constant. It goes up when the negative sequence current goes down. For a small negative sequence current a higher negative sequence impedance occurs. This is caused by the non saturated tips of the rotor teeth. The tested data clearly show that the no load negative sequence current of 4.2 Amps is significantly smaller than the negative sequence current of $13.7 \mathrm{Amps}$ at full load. The no load loss does not cover most of the negative sequence losses when the motor is loaded.

\begin{tabular}{|c|c|c|c|c|c|}
\hline \multirow{2}{*}{ Load } & \multicolumn{2}{|c|}{$\begin{array}{c}\text { Positive } \\
\text { Sequence. }\end{array}$} & \multicolumn{2}{c|}{$\begin{array}{c}\text { Negative } \\
\text { Sequence }\end{array}$} & \multirow{2}{*}{ Ratio } \\
\cline { 2 - 5 } & $\begin{array}{c}\text { V+ } \\
\text { [V] }\end{array}$ & $\begin{array}{c}\text { It } \\
\text { [Amp] }\end{array}$ & $\begin{array}{c}\text { V- } \\
\text { [V] }\end{array}$ & $\begin{array}{c}\text { I- } \\
\text { [Amp] }\end{array}$ & \\
\hline $100 \%$ & 451.5 & 60.0 & 20.9 & 13.7 & 1.53 \\
\hline $75 \%$ & 452.8 & 43.7 & 20.8 & 12.8 & 1.62 \\
\hline $50 \%$ & 454.2 & 30.8 & 20.4 & 11.5 & 1.78 \\
\hline $25 \%$ & 455.4 & 19.0 & 18.7 & 8.6 & 2.17 \\
\hline $0 \%$ & 457.9 & 12.2 & 16.0 & 4.2 & 3.81 \\
\hline
\end{tabular}

Table 1. Tested fundamental frequency positive and negative sequence components of voltages and currents of a $50 \mathrm{Hp}$ motor under an unbalanced supply.

In Method E the input power is used as the base to subtract various losses for the output power. The load 
dependent negative sequence losses that are not included in the no load loss increase the input power. Subsequently, the output power is evaluated to be higher. On the contrary, the air-gap torque method uses the air-gap torque power, not the input power, as the starting point of loss subtraction for the output power evaluation. The losses associated with negative sequence currents are calculated for each load. The air-gap torque method recognizes the sign difference between the torque and the corresponding input power. For example: the input power of the fundamental negative sequence voltage and currents is positive, but the air-gap torque is negative. After the air gap torque power is found, one subtracts the estimated stray load loss and the no load air gap torque power that includes the friction and windage loss and the core loss to find the output power.

For three-phase four-lead motors, two line voltages and three line currents need to be measured for air-gap torque calculations [2]. For three-phase three-lead motors, waveforms of two line voltages and two line currents are required.

\section{H. Shaft Torque Method:}

Regardless how sophisticated a method is, it remains difficult to assess all the stray load losses accurately in the field. The most straightforward method is to measure the output power directly from the shaft without any need to calculate losses. The shaft torque method offers the most accurate field efficiency evaluation method. It is also highly intrusive.

A custom-built torque coupling may be used to replace the existing coupling. Torque signals can be obtained through slip rings. Laser and telemetry technologies may also be used without going through slip rings for signal noise reductions. Many different ways have been proposed (see Reference Section of [1]). The accuracy of this method depends on the quality of the torque sensors, the signal noise, and the shaft alignment of motor and its load. Downtime is required for preparing and replacing the shaft torque coupling.

\section{ACCURACY CONSIDERATION}

\section{A. Accuracies of Basic methods}

Although more rigid accuracy evaluation of field efficiency measurement is needed, accuracy estimation of measured efficiency presently is based on experience.

For NEMA frame motors, the nameplate efficiency is commonly stamped according to Method B of IEEE-112 Std. Bonnett [9] suggests that with the use of existing technologies it is unreasonable to expect accuracies of efficiency for the following items better than those shown below:

-Accuracy of calculations: \pm 0.5 Pts of Eff.

-Manufacturing and material variations: \pm 0.5 Pts of Eff.

- Test accuracy: \pm 0.5 Pts of Eff.

A total of \pm 1.5 Pts of Eff in Bonnett's opinion is the simple summation of the three factors that he considered. It is not the square root of the sum of accuracy squares, which

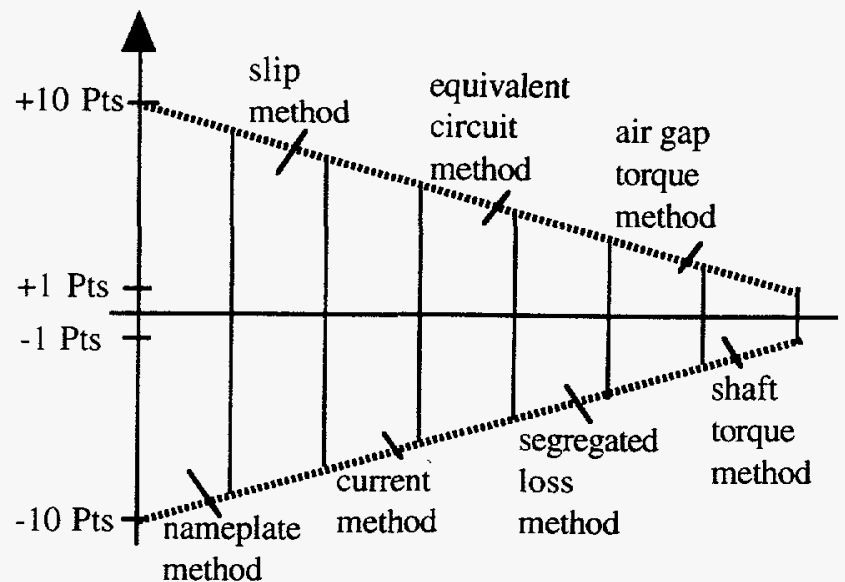

Fig. 5 Efficiency anticipated accuracies versus basic element methods for loads between full and half load. (Additional equipment accuracy tolerances need to be added to those shown in this figure.)

is a commonly used method.

For various basic methods, the best accuracy is provided by the torque gauge method. It may have an accuracy of $\pm 1 \%$, which is in line with Bonnett's manufacturing and test accuracies.

Fig. 5 shows a coarse estimation of possible accuracies of various basic methods. The rationale is that we know the least accurate method is the nameplate method; it has the worst accuracy of $\pm 10 \%$ for loads between half and full. The best accuracy is provided by the torque gauge method. It has an accuracy of $\pm 1 \%$. All the other methods that are partially involved with either nameplate data and/or statistical values fall in between these two extreme basic methods. The less use of nameplate information and the more reliance on direct measurement without assumed values for efficiency evaluation the better the accuracy would be. The inaccuracies, in general, are worse below $50 \%$ load.

The statistical or empirical method can provide a wide range of accuracy. It depends on the sample population and the application range. Intuition tells us that a well targeted sample range for a small application range normally gives high accuracy. For example, empirical equations obtained from data of one specific sample motor can be very accurate when they are applied for the same specific motor. The accuracy becomes extremely poor when the one sample conclusion is applied to a totally different motor. This is the reason the empirical method is not included in Fig. 5.

\section{B. Measurement Consideration}

\section{Instruments}

IEEE Std. 112 [10] requires high-accuracy instruments, with individual errors of less than $\pm 0.5 \%$ of full scale, 
including both amplitude and phase angle effects. There are indications that revisions to the standard will require even greater accuracy.

For field measurements, instrument accuracy is an important issue. When either temporary, portable instruments or permanently installed instruments that are not intended for precision metering are used, such accuracies can be extremely difficult to achieve. Portable monitoring instruments typically consist of clamp-on current transformers or Hall-effect pickups and some means of voltage transduction. Some clamp-on style probes are available with manufacturer specified amplitude accuracies approaching $0.5 \%$, but even for these high accuracy clampon probes, there are practical considerations that can considerably reduce actual accuracies. The practical accuracy, for power monitoring purposes, is dependent upon both phase angle and amplitude. The phase angle shift of transformers is typically dependent upon current amplitude. If compensation for phase angle shift is not provided, the associated error (for power/power factor consideration purposes) can be significantly greater than amplitude errors. For example, a phase angle shift of $1.5^{\circ}$, which is typical for high accuracy clamp-on transformers (although some have much greater shifts), would result in a power/power factor indication error of about $3 \%$ at an actual power factor of 0.7 , if compensation for the phase shift is not made. Since, as noted above, phase shift is a function of amplitude, it is a difficult proposition to provide full bandwidth compensation.

Two other factors that can greatly influence clamp-on accuracies are proper jaw closure and conductor centering. Hall-effect probes are typically more affected by centering considerations, and both Hall-effect and transformers are significantly affected by proper jaw closure and alignment factors. The exact magnitude of both amplitude and phase angle affects can vary considerably, but errors for noncentered conductors (particularly for Hall-effect probes) can easily exceed $1 \%$. Errors associated with improper jaw closure can easily exceed $1 \%$ amplitude and phase angle shifts of greater than $5^{\circ}[1]$.

\section{Measurement duration}

Particularly for measurements done in the field, it is important to recognize that the load of many machines fluctuates significantly, both over the long term (for instance from changing plant conditions) as well as the short term (for example, load fluctuations from belt drives). In order to ensure that data accurately reflects the true average load, it is usually necessary to collect either several samples and develop a statistically valid measure or to acquire a relatively long sample of data (long can range from a few seconds to minutes, depending on the nature of the load). Belt-driven devices, in particular, can cause relatively large load fluctuations (as much as $10 \%$ or more) at belt passing speed. Thus, a single short duration sample (for example a few cycles in length) may grossly misrepresent the actual average load condition.

\section{Importance of errors}

The importance of a particular error source is entirely dependent upon what is done with the measurement result. For example, if speed measurement is made in a laboratory, and the speed is used, along with torque, to calculate shaft power, an error of $0.05 \%$ in speed corresponds to an error of $0.05 \%$ in calculated shaft power, and ultimately to an error of $0.05 \%$ in calculated efficiency. On the other hand, if an error of $0.05 \%$ in speed (slightly less than $1 \mathrm{rpm}$ for a fourpole motor), is made in a field measurement, the consequences can be entirely different. If motor efficiency, not actual power, is the subject of interest, and efficiency is estimated from either vendor curves of efficiency vs. load or from motor models, the effect of the speed error will be very minor as long as the actual motor operation is between half load and full load. This is simply an inherent result of the typically flat efficiency vs. load profile for motors operated in this zone. However, if the interest is in estimating power rather than motor efficiency, a $1 \mathrm{rpm}$ error would translate into roughly a $5 \%$ error in power estimate for a four-pole motor with a rated load speed of $1780 \mathrm{rpm}$.

For lightly loaded conditions (less than $25 \%$ power), errors from all sources tend to be magnified. Any phase shift error in transducers is much more important at low power factors [1]. Also, because the slope of the motor efficiency vs. load curve is very steep at light load conditions, even very minor errors in speed can translate into large efficiency estimate errors if speed is the only available measurement and motor performance curves or models are used.

The accumulated equipment accuracies, especially when low grade instrumentation is used, have to be added to the accuracy estimations. A common method for estimating accumulated accuracies is to use the square root of the sum of their squares.

\section{SAMPLES OF FIELD EFFICIENCY EVALUATION RESUlTS}

Efficiencies obtained from seven different induction motor field evaluation methods [1] (i.e., shaft-torque, current, slip, Stanford-Wilke (a statistical method), OntarioHydro-Modified (O.H.M.), Nameplate Equivalent Circuit (N.E.C.), and air-gap-torque) are plotted against percentage of load in Fig. 6. The shaded curve is the actual efficiency obtained from the shaft torque method. The slip and current methods show greater than $20 \%$ discrepancies from the true efficiency. This indicates that certain statistical elements in these two methods are not suitable to be used for the test motors. It should be noted that with proper statistical data, the slip and current methods may still be possible to give better results than the two packages used in this test.

A sophisticated version of air gap torque method [2], which uses only one statistical value (IEEE Std 112 stray load loss percentage), but requires an uncoupled no load test, gives consistently accurate results. It is suitable for field efficiency evaluations of a wide range of motors. 


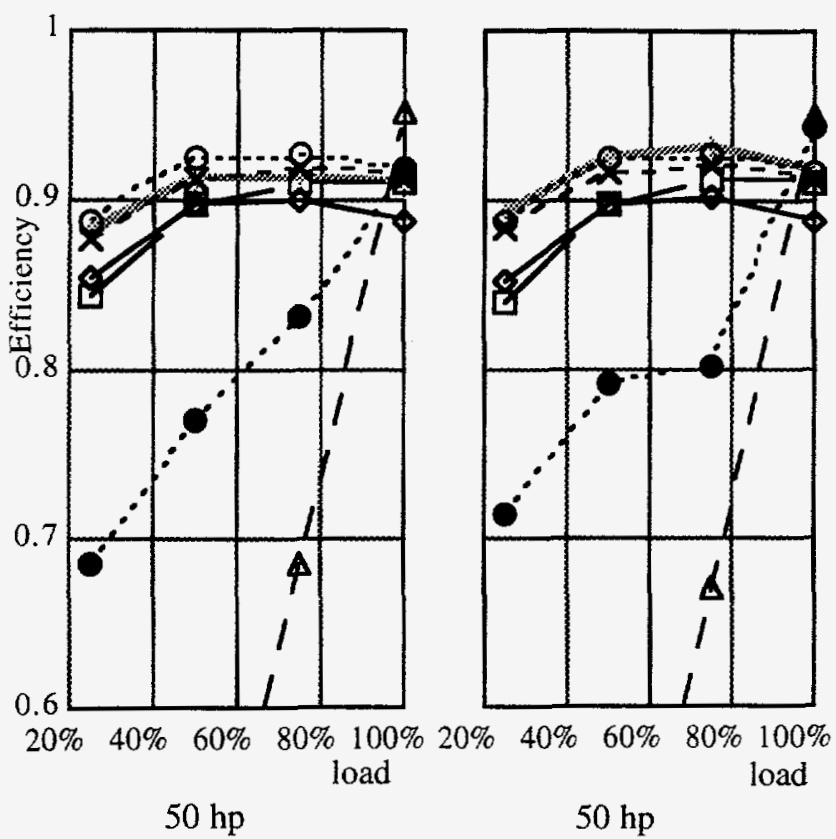

with unbalanced voltage

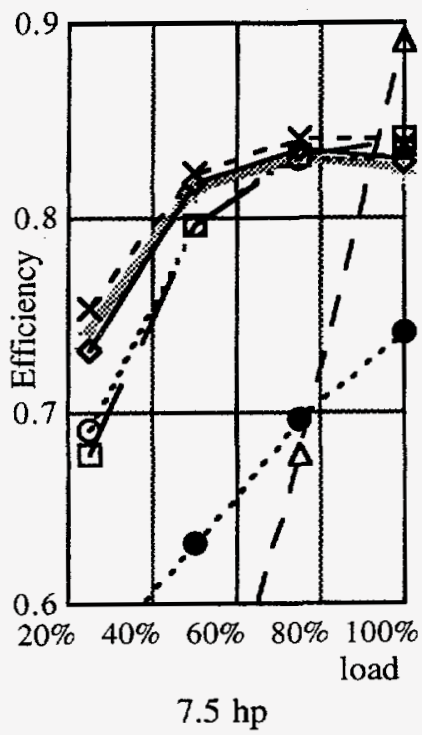

with unbalanced voltage

Fig. 6 Samples of field efficiency evaluation results. Legend of curves is given in the right hand side. with balanced voltage

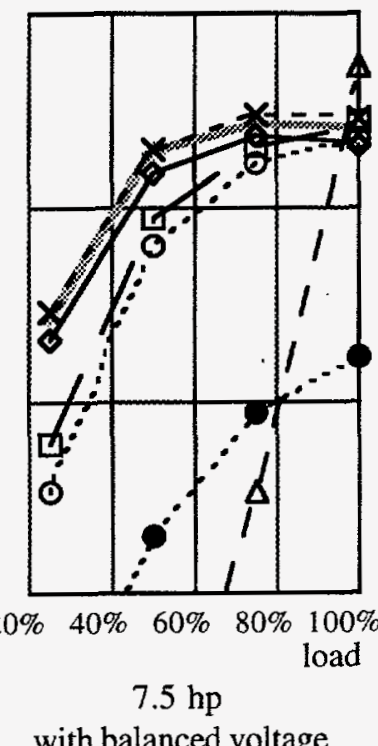

with balanced voltage

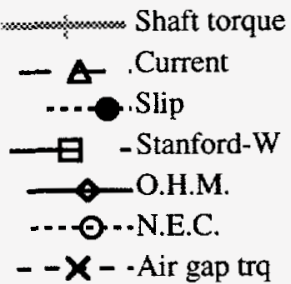

The Nameplate Equivalent Circuit Method, which has a very low level of intrusiveness (only a measurement of speed is required), but relies on statistical data heavily, gives good results for loads above $50 \%$. It is suitable for a targeted group of motors.

\section{Conclusions}

1) A field efficiency evaluation method can be built on different basic methods such as equivalent circuit with empirical parameters. This combined approach normally improves the accuracy and reduces intrusiveness of efficiency evaluation for a targeted group of motors. Regardless how complex the combination is, the nature of each basic method affects the combination.

2) This paper compares the physical natures (i.e., theoretical bases and error sources) of basic methods contained in various available field efficiency evaluation methods.

3) The basic methods are: nameplate method, slip method, current method, statistical method, segregated loss method, equivalent circuit method, air gap torque method, and shaft torque method.

4) The intrusiveness or cost and accuracy are the major considerations for selecting a field-efficiency evaluation method. Users want a lower intrusive method under a given accuracy requirement.

5) The least intrusive and least accurate method is the nameplate method. The most intrusive and most accurate basic method is the shaft torque method. Accuracy evaluation in this paper is based on published opinions rather than on rigorous statistical exercises.

6) The average load factor of motors operating in the field is around $75 \%$. Reexamination of the chosen method and the measurements should be conducted when the difference between the evaluated efficiency and the nameplate efficiency is greater than 10 percentage points.

7) The sophisticated version of the air gap torque method can have a certain advantage over the segregated loss method when the unbalance and harmonic content of the supply system are not negligible.

8) The shaft torque method dores not rely on any assumed loss such as the stray load loss but is very instrusive.

9) Statistical approaches can be very effective. A good example is the Nameplate Equivalent Circuit Method. For a targeted group of motors, it provides a significant improvement in accuracy over the slip method with no increase in intrusiveness.

10) Statistical approaches can also be damaging when it is not used for the targeted group of motors. A good example is the poor result of slip and current methods shown in Fig. 6.

11) We hope that this paper may help field engineers to select or to establish a proper efficiency evaluation method by understanding the different basic methods, their theoretical foundations and error sources.

\section{ACKNOWLEDGMENTS}

The authors would like to thank the Office of Energy 
Efficiency and Renewable Energy, U.S. Department of Energy for financial support through the Motor Challenge Program. Thanks are due to the Oak Ridge National Laboratory (ORNL) for the support staff and facilities provided for the research work. The authors would like to express their appreciation to Paul Scheihing, DOE program manager, and Donald Adams, ORNL group manager, for their support in this research.

The selected use of information and data given in the survey of "Assessment of Available Methods for Evaluating In-Service Motor Efficiency" by J. D. Kueck, J. R. Gray, R. C. Driver, J. S. Hsu, P. J. Otaduy, and L. M. Tolbert is gratefully acknowledged. The survey was prepared for the U.S. Department of Energy, Bonneville Power Administration and the Pacific Gas and Electric Company.

\section{REFERENCES}

[1] J. D. Kueck, M. Olszewski, D. A. Casada, J. S. Hsu, P. J. Otaduy, L. M. Tolbert, "Assessment of Methods for Estimating Motor Efficiency and Load under Field Conditions," ORNL/TM-13165, January 1996, Lockheed Martin Energy Research Corp.

[2] John S. Hsu, Patrick L. Sorenson, "Field Assessment of Induction Motor Efficiency through Air-Gap Torque," IEEE/PES 1996 Winter Meeting, Paper 96 WM-130-5EC.

[3] HIGH EFEICIENCY MOTOR SELECTION HANDBOOK, Bonneville Power Administration (BPA), 1990, p.21.

[4] William D., Biesemeyer, Jeffrey Jowett, "Facts and Fiction of HVAC Motor Measuring for Energy Savings," Biesemeyer \#116, Arizona Department of Commerce Energy Office.

[5] Philip L. Alger, THE NATURE OF INDUCTION MACHINES, Gordon and Breach, 1965.

[6] J. S. Hsu, H. H. Woodson, and W. F. Weldon, "Possible Errors in Measurement of Air-Gap Torque Pulsations of Induction Motors," IEEE Transactions on Energy Conversion, March 1992, Vol. 7, No. 1. ITCNE4, pp202-08.
[7] John S. Hsu, "Monitoring of Defects in Induction Motors through Air-Gap Torque Observation," IEEE Transactions on Industry Applications, September 1995, Vol. 31, No. 5, ITIACR, (ISSN 0093-9994), pp. 1016-21.

[8] C. L. Becnel et al., "Determining Motor Efficiency by Field Testing," IEEE Transactions on Industry Applications, Vol. IA-23, No. 3, 1987.

[9] Austin H. Bonnett, "An Update on AC Induction Motor Efficiency," IEEE Transactions on Industry Applications, Vol. 30, No. 5, September/October 1994.

[10] IEEE Standard Test Procedure for Polyphase Induction Motors and Generators, IEEE Std 112-1991, IEEE Power Engineering Society, New York, NY.

[11] H. E. Jordan, A. Gattozzi, "Efficiency Testing of Induction Machines," IAS79:9C, Petroleum and Chemical Industry Committee, IAS/IEEE, pp.284-289.

[12] Robert E. Oesterlei, "Motor Efficiency Test Methods-Apple and Oranges?" Power Transmission Design, 22 (5); pp. $41-43$, May 1980

[13] W. D. Bowers, P. G. Cummings, W. J. Martiny, "Induction Motor Efficiency Test Methods," IEEE, PCI-78-8B.

[14] NEMA Standards Publication Number MG1, National Electrical Manufacturers' Association (NEMA), Washington DC, 1993.

[15] Motor Master, Version 2.1, Washing State Energy Office, P. O. Box 43165, Olympia, WA 98504-3165.K.

[16] R. L. Nailen, "Can Field Tests Prove Motor Efficiency?' IEEE Conference Record of Industrial and Commercial Power Systems Technical Conference, 1988 May 2-5, Baltmore, MD, pp.110-116.

[17] John S. Hsu, Pedro J. Otaduy, John D. Kueck, "Efficiency and Reliability Assessments of Retrofitted High-Efficiency Motors," Conference Record of 1995 IEEE 30th IAS Annual Meeting, October, 1995, Orlando, Florida, pp. 2745-51.

[18] John S. Hsu, Brian P. Scoggins, "Field Test of Motor Efficiency and Load Changes through Air-Gap Torque," IEEE Transactions on Energy Conversion, September 1995, Vol. 10, No. 3, ITCNE4 (ISSN 0885-8969), pp. 471-77.

[19] Understanding A-C Motor Efficiency Electrical Apparatus Service Association, St. Louis.

\section{DISCLAIMER}

This report was prepared as an account of work sponsored by an agency of the United States Government. Neither the United States Government nor any agency thereof, nor any of their employees, makes any warranty, express or implied, or assumes any legal liability or responsibility for the accuracy, completeness, or usefulness of any information, apparatus, product, or process disclosed, or represents that its use would not infringe privately owned rights. Reference herein to any specific commercial product, process, or service by trade name, trademark, manufacturer, or otherwise does not necessarily constitute or imply its endorsement, recommendation, or favoring by the United States Government or any agency thereof. The views and opinions of authors expressed herein do not necessarily state or reflect those of the United States Government or any agency thereof. 